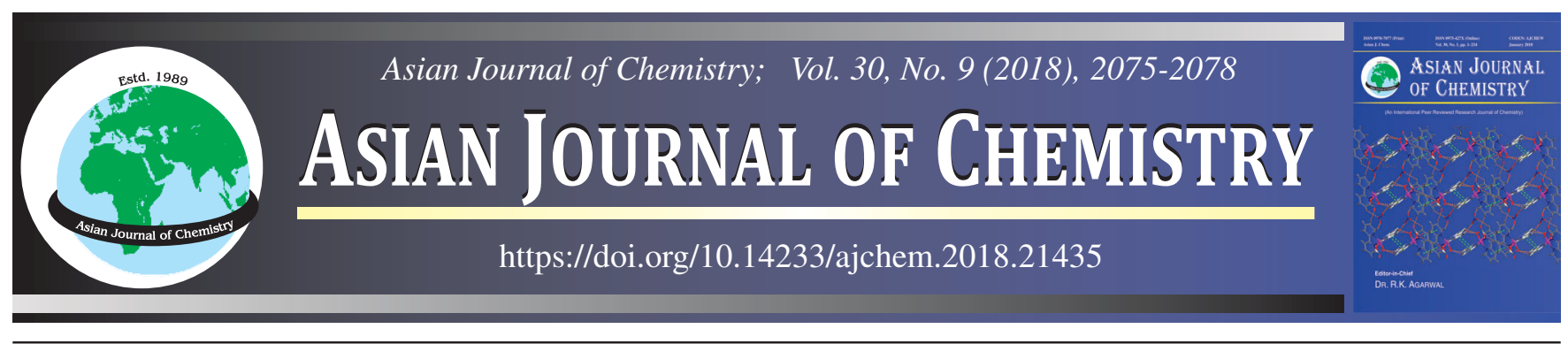

\title{
Effect of Ultraviolet Radiation on CN-85 and CR-39 Detectors by UV-Visible Spectroscopy and (He-Ne) Laser Penetration Techniques
}

\author{
Hussain Ali Al-Jobouri ${ }^{1, *}$, WiJdan Thamer FAaZ ${ }^{1}$ and Laith A. NaJAM ${ }^{2}$
}

${ }^{1}$ Department of Physics, College of Science, Al-Nahrain University, Baghdad, Iraq

${ }^{2}$ Department of Physics, College of Science, University of Mosul, Mosul, Iraq

*Corresponding author: E-mail: hahmed54@gmail.com

Received: 9 May 2018;

Accepted: 27 June 2018;

Published online: 31 July 2018;

AJC-19023

Nuclear track detectors (NTDs) are affected by particulate and non-particulate radiations. However, the effect of ultraviolet radiatio, (as an electromagnetic non particulate) radiation was determined by changes in spectroscopic and optical parameters of irradiated nuclear track detectors. Nuclear track detectors, namely CR-39 and CN-85 were UV-irradiated at a fixed distance using a stable Pen ray UV lamp emitting wavelength $(\lambda)$ at $254 \mathrm{~nm}$. UV-visible spectroscopy was used to elucidate the effect at varying $U$ V-exposure time $\left(\mathrm{T}_{\mathrm{uv}}\right)(30-180$ $\mathrm{min})$. For measuring the optical changes of UV-irradiated nuclear track detectors, variations in penetration rate - $\mathrm{P}$ and laser penetration factor- $F_{p}$ of $\mathrm{He}-\mathrm{Ne}$ laser beam was used. The maximum absorbance $(\mathrm{A})$ at wavelengths $234 \mathrm{~nm}\left(\mathrm{~A}_{234}\right)$ and $260 \mathrm{~nm}\left(\mathrm{~A}_{260}\right)$ was greater in $\mathrm{CN}-85$ in comparison to $\mathrm{CR}-39$. This coincides with $(\mathrm{P})$ and $\left(\mathrm{F}_{\mathrm{P}}\right)$ of laser penetration. Furthermore, a linear relationship between absorbance $\mathrm{A}_{234}$ and $\mathrm{A}_{260}$ with UV-exposure time ( $\mathrm{T}_{\mathrm{uv}}$ ) was detected in both detectors. Howoever, a polynomial relationship between laser penetration factor $\left(\mathrm{F}_{\mathrm{p}}\right)$ and $\mathrm{UV}$-exposure time $\left(\mathrm{T}_{\mathrm{uv}}\right)$ was also observed. It could, therefore, be concluded that both detectors are suitable for UV-dosimetry at dose range applied in this study. Hence, the case of the technique may prove practical in some environmental and medical applications.

Keywords: Nuclear track detector CR-39, Ultraviolet radiation, He-Ne laser, UV-visible spectroscopy.



\section{INTRODUCTION}

Nuclear track detectors (NTDs) are known to be molecularly influenced by particulate and non-particulate radiations. Photothermal spectroscopy, image analysis as well as their optical band gap were used to detect the changes in the thermal and optical properties of the these detectors [1-3].

In those studies $\alpha$ - and neutron-induced tracks were measured by the He-Ne laser transmission technique [4]. On the other hand, the effect of non-particulate radiation (ionizing and non-ionizing), were also studied using CR-39 and CN-85 detectors $[4,5]$ at UV-visible, Fourier transform infrared-FTIR spectra [6] and, $\mathrm{CO}_{2}$ diffusion [7]. The corresponding $\gamma$-dose from measured etched tracks was then calculated [7]. Accordingly, CR-39 and Lexan detectors were calibrated as lowLET radiation dosimeters $[8,9]$.

Kumar et al. [2,3] determined the effect of ionizing radiation on CR-39 polymer. The effect of X-rays on CR-39 plastics was observed in UV-visible, Fourier transform infrared spectra
[6] and by $\mathrm{CO}_{2}$ diffusion [7]. The $\gamma$-radiation used for obtaining the structural modifications and the track registration response of some $\gamma$-irradiated polycarbonate detectors were measured by Sinha et al. [8]. Moreover, CR-39 and Lexan detectors were calibrated as low-LET radiation dosimeters $[8,9]$.

The effect of non-ionizing radiation (IR, UV and laser) on nuclear track detectors was studied by Parashar et al. [10] by determining the effect of IR irradiation on some polymers in which they studied the modifications owing to irradiation by analyzing the XRD and UV-visible spectra. Rafique et al. [11] reported that the nonlinear absorption increases with increasing $\mathrm{He}-\mathrm{Ne}$ laser fluencies by using AFM and Raman spectroscopy. The effects of UV radiation on nuclear track detectors were studied by Wong et al. [6]. A comparison between these effects of UV radiation on CR-39 and Lexan detectors which was irradiated by $\alpha$ particles was achieved.

For this purpose, Shweikani et al. [12] used three techniques: (1) alpha track diameters and track densities, (2) UV-visible spectrometry and (3) FTIR spectrometry. These techniques

This is an open access journal, and articles are distributed under the terms of the Creative Commons Attribution-NonCommercial 4.0 International (CC BY-NC 4.0) License, which allows others to copy and redistribute the material in any medium or format, remix, transform, and build upon the material, as long as appropriate credit is given and the new creations are licensed under the identical terms. 
were used to determine the effect of solar ultraviolet (SUV) and ultraviolet type A-UVA on CR-39 detectors.

The FTIR spectroscopy technique was used to determine of UV radiation on polyallyldiglycol carbonate (PADC) films were used for measuring the parameters such as the size of $\alpha$-particle tracks, track etch rate and detector sensitivity [14]. Several techniques were used for determining the effect of UV radiation on nuclear track detectors. UV-visible spectrowith exposure time for CR-39 track detector [15].

Zaki et al. [16] used UV irradiation to reduce the track formation time on thin PADC films by using FTIR spectrometry. FTIR spectrometry and UV-visible spectrometry techniques were used to determine the possibility of using nuclear track detectors CR-39 as UV dosimeters [12]. In this study, the effect of UV irradiation is calculated for CR-39 and CN85 detectors as UV-radiation dosimeters by using UV-visible spectroscopy and laser penetration techniques.

\section{EXPERIMENTAL}

Two types of nuclear track detectors were used in this study. The first one was $\mathrm{CN}-85$ detectors with thickness 250 $\mu \mathrm{m}(1 \mathrm{~cm} \times 1 \mathrm{~cm})$ and density $1.42 \mathrm{~g} . \mathrm{cm}^{-3}$, manufactured by the Eastman Kodak Company, Rochester, New York and having a chemical formula $\mathrm{C}_{6} \mathrm{H}_{8} \mathrm{O}_{9} \mathrm{~N}_{2}$. The second type of nuclear track detectors was the CR-39 detector with thickness $200 \mu \mathrm{m}$ $(1 \mathrm{~cm} \times 1 \mathrm{~cm})$ and density $1.32 \mathrm{~g} . \mathrm{cm}^{-3}$, supplied by TASTRAK type (Track Analysis System Ltd.), UK and having a chemical formula $\mathrm{C}_{12} \mathrm{H}_{18} \mathrm{O}_{7}$.

The arrangement setup of ultraviolet lamp, both detectors (CR-39 or CN-85), jack (holder), timer and power supply is shown in Fig. 1.

CR-39 and CN-85 detectors are exposed to UV irradiation at a wavelength- $\lambda$ of $254 \mathrm{~nm}$ by using a UV lamp source type PEN-Ray Lamp Company SAN GARIEL Inc. The distance between UV lamp source and NDTs samples (CR-39 or CN85 ) was $15 \mathrm{~cm}$. CR-39 or CN-85 detectors were irradiated with UV radiation in a dark room. UV- exposure times- $\mathrm{T}_{\mathrm{uv}}$ were 30 , 60, 120, 150 and $180 \mathrm{~min}$. UV-visible spectroscopy technique was used for measuring the optical absorbance-A of CN-85 and CR-39 detectors. UV-visible spectroscopy system from the effect of UV irradiation on CR-39 detectors [13]. The effect scopy technique was used for calibrating the UV-radiation dose

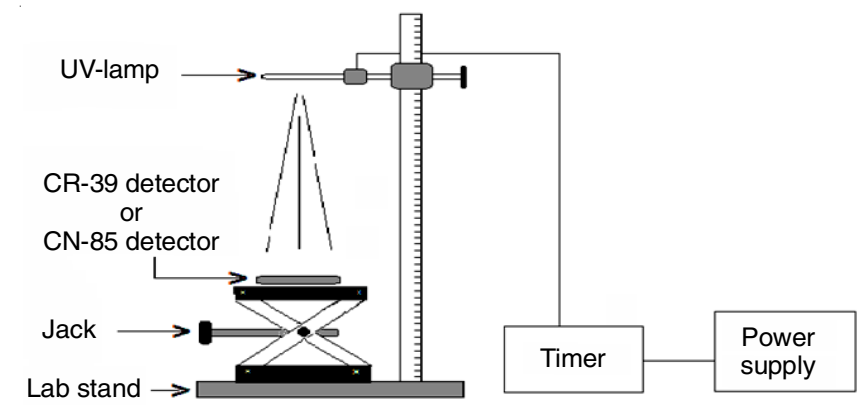

Fig. 1. Ultraviolet irradiation setup for both detectors (CR-39 or CN-85), UV lamp, Jack (holder), timer and power supply

Jasco, Model V-670 with a scan speed of $200 \mathrm{~nm} / \mathrm{min}$, in the range of 200-900 $\mathrm{nm}$ was used. The absorbance-A for CR-39 and $\mathrm{CN}-85$ was meassurmed at the wavelengths $260 \mathrm{~nm}$ and $234 \mathrm{~nm}$, since these wavelengths have the maximum response to UV-radiation [17].

Laser penetration technique was used for measuring the penetration rate-P of $\mathrm{He}-\mathrm{Ne}$ laser with power $15 \mathrm{~mW}$ and wavelength $632 \mathrm{~nm}$. The spectrofluorophotometer model (RF1501 Shimadzu, Ltd.) was used for measuring the penetration rate-P, at a distance of $13 \mathrm{~cm}$ from the detector.

\section{RESULTS AND DISCUSSION}

UV-visible technique was used for measuring the UVvisible spectrum at a range of 200-350 nm for CR-39 and CN85 detectors after $\mathrm{UV}$-exposure time $\mathrm{T}_{\mathrm{uv}}$ with periods 30,60 , 120, 150, $180 \mathrm{~min}$ ). UV-visible spectra are shown in Fig. 2 for CR-39 and CN-85 detectors. For both detectors, Fig. 2 shows an increase in the values of absorbance-A with an increase in UV-exposure time $T_{\text {uv }}$ from $30 \mathrm{~min}$ to $180 \mathrm{~min}$. The maximum absorbance-A, for the CR-39 detector at $180 \mathrm{~min}$ (UV-exposure time $\mathrm{T}_{\mathrm{uv}}$ ) was 4.79 at a wavelength of $204.7 \mathrm{~nm}$ (Fig. 2a).

The maximum absorbance-A, for the $\mathrm{CN}-85$ detector at $180 \mathrm{~min}$ (UV-exposure time- $\mathrm{T}_{\mathrm{uv}}$ ) was 3.99 at a wavelength of $277.3 \mathrm{~nm}$ (Fig. 2b). For CR-39 and CN-85 detectors, the relationship between UV-irradiation time- $\mathrm{T}_{\mathrm{uv}}$ and absorbanceA at wavelengths $234 \mathrm{~nm}\left(\mathrm{~A}_{234}\right)$ and $260 \mathrm{~nm}\left(\mathrm{~A}_{260}\right)$ are shown in Figs. 3 and 4, respectively.

The mathematical behaviour of $\mathrm{T}_{\mathrm{uv}}$ with $\mathrm{A}_{234}$ and $\mathrm{A}_{260}$ is a linear relationship, as shown in Table-1 for CR-39 and CN-85

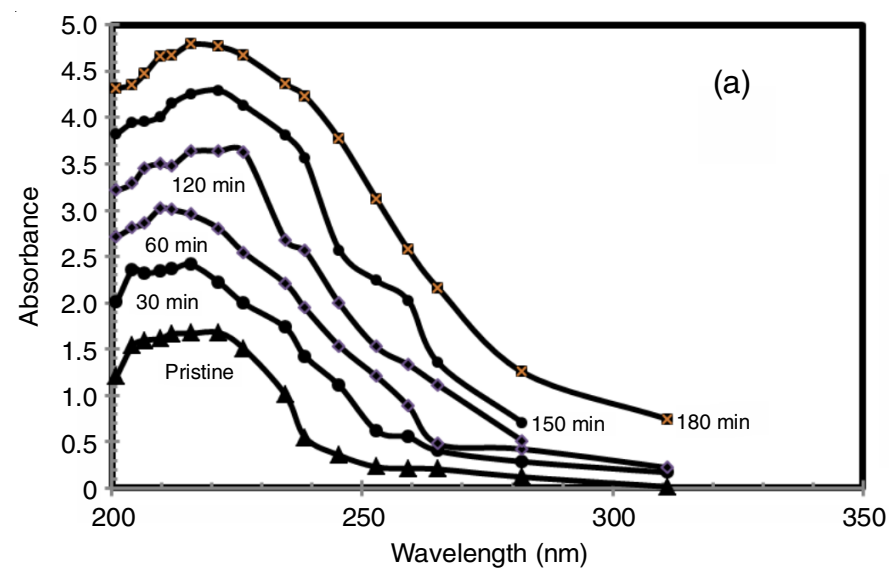

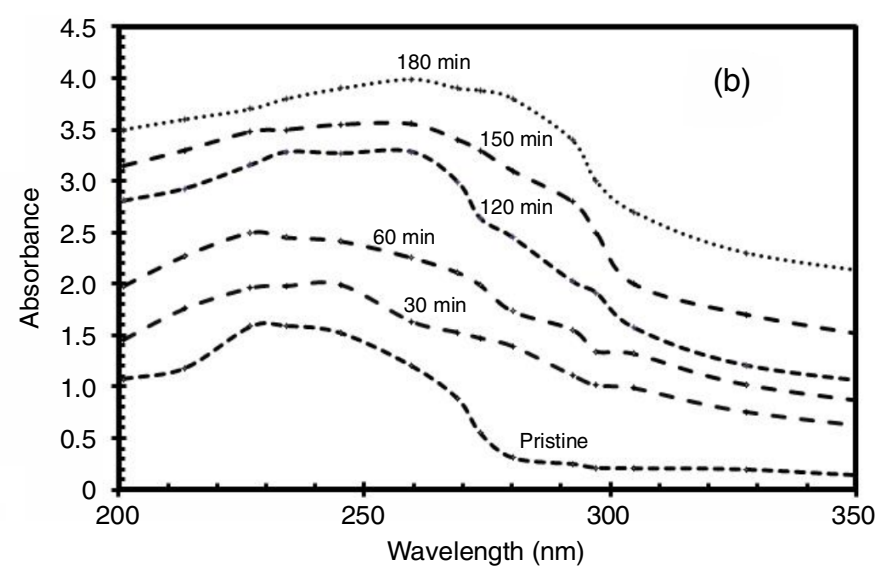

Fig. 2. UV-visible spectra at a range of $200-350 \mathrm{~nm}$ of pristine and UV-irradiated detectors with UV-exposure time $\mathrm{T}_{\mathrm{uv}}(30,60,120,150$ and 180 min) comparing with pristine sample; (a) CR-39 detector, (b) CN-85 detector 

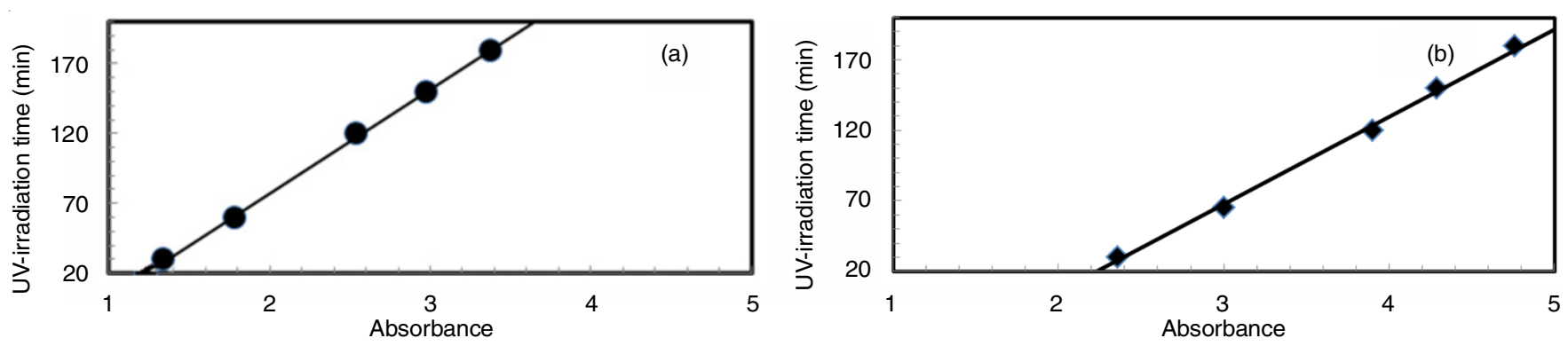

Fig. 3. Variation of UV-irradiation time- $\mathrm{T}_{\mathrm{uv}}(\mathrm{min})$ as a function of absorbance-A at wavelength $234 \mathrm{~nm}$ for (a) $\mathrm{CR}-39$ detector and (b) $\mathrm{CN}-85$ detector
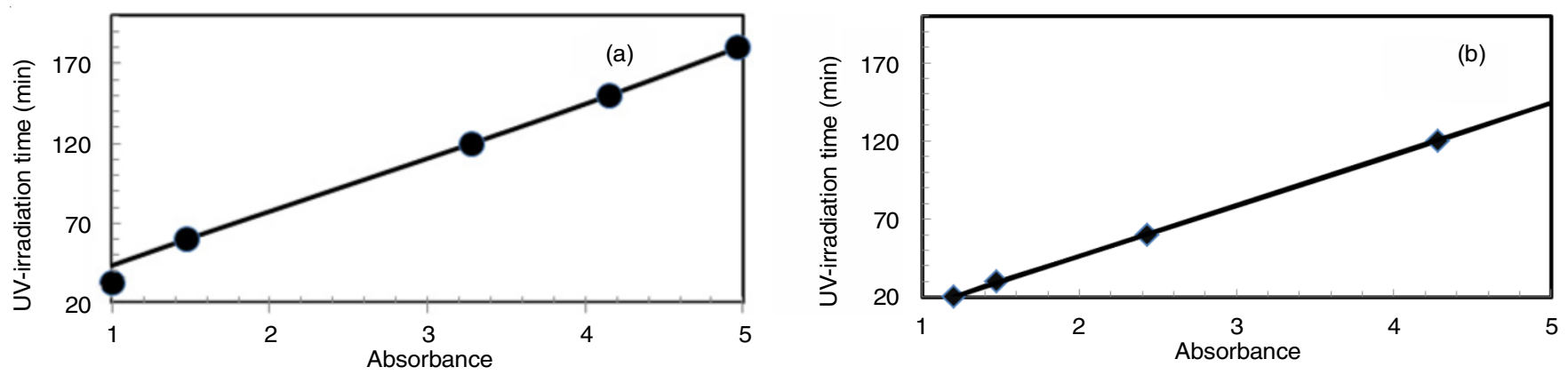

Fig. 4. Variation of UV-irradiation time- $\mathrm{T}_{\mathrm{uv}}(\mathrm{min})$ as a function of absorbance-A at wavelength $260 \mathrm{~nm}$ for (a) $\mathrm{CR}-39$ detector and (b) $\mathrm{CN}-85$ detector

detectors. Moreover, the linear relationship between $\mathrm{T}_{\mathrm{uv}}$ and the values of absorbance-A determines the relationship between the increase of UV-exposure time of the CR-39 detector with the increase of absorbance-A difference at wavelengths 350 $\mathrm{nm}$ and $550 \mathrm{~nm}[15]$.

\begin{tabular}{|c|c|c|}
\hline \multicolumn{3}{|c|}{$\begin{array}{l}\text { LINEAR RELATIONSHIP EQUATIONS FOR ABSORBANCE (A) } \\
\text { AT WAVELENGTHS } 234 \text { nm AND } 260 \mathrm{~nm} \text { WITH UV- } \\
\text { IRRADIATION TIME }\left(\mathrm{T}_{\mathrm{uv}} \text { ) FROM } 30 \mathrm{~min} \text { TO } 180 \mathrm{~min}\right. \\
\text { FOR CR-39 AND CN-85 DETECTORS }\end{array}$} \\
\hline \multirow{2}{*}{ Detector } & \multicolumn{2}{|c|}{ Linear relationship equations at wavelength } \\
\hline & $234 \mathrm{~nm}$ & $260 \mathrm{~nm}$ \\
\hline CR-39 & $\mathrm{T}_{\mathrm{uv}}=74.7 \mathrm{~A}_{234}+71.3$ & $\mathrm{~T}_{\mathrm{uv}}=33.7 \mathrm{~A}_{260}+10$ \\
\hline $\mathrm{CN}-85$ & $\mathrm{~T}_{\mathrm{uv}}=62.1 \mathrm{~A}_{234}-117.9$ & $\mathrm{~T}_{\mathrm{uv}}=32.6 \mathrm{~A}_{260}-18.9$ \\
\hline
\end{tabular}

The values of $\mathrm{A}_{234}$ (Fig. 3b) and $\mathrm{A}_{260}$ (Fig. 4b) for the CN-85 detector were greater than those for the CR-39 detector. This observation indicates that the $\mathrm{CN}-85$ detector is more sensitive to UV-radiation than the CR-39 detector. This behaviour of sensitivity for CN-85 and CR-39 detectors is reported by Zaki et al. [16] by calculating the energy density of the laser beam for $\alpha$-particle irradiation on these detectors. The UV response of CR-39 and CN-85 detectors at $234 \mathrm{~nm}$ (Fig. 3), were obtained in other studies at a wavelength $235 \mathrm{~nm}$ by determining the differential of UV-absorption spectra of CR39 irradiated with protons at a different fluence [18]. El-Farrash et al. [19] reported that the exposure to UV radiation increases the mean track size, bulk etch rate and track etch rate of the CR-39 detector at two peaks corresponding to 254 and $350 \mathrm{~nm}$ lines and decreases at $300 \mathrm{~nm}$. Table- 1 shows the linear relationship equations concering $\mathrm{A}_{234}$ and $\mathrm{A}_{260}$ for CR-39 and CN-85 detectors with $\mathrm{T}_{\mathrm{uv}}$. The values of $\mathrm{T}_{\mathrm{uv}}$ for $\mathrm{CR}-39$ and $\mathrm{CN}-85$ detectors were calculated by using the equations in Table-1 after determination the values of $\mathrm{A}_{234}$ and $\mathrm{A}_{260}$.
Fig. 5 shows the behaviour of relationship to laser penetration rate $\mathrm{P}$ with $\mathrm{T}_{\mathrm{uv}}$ for $\mathrm{CR}-39$ and $\mathrm{CN}-85$ detectors compared to un-irradiated detectors at $\mathrm{T}_{\mathrm{uv}}=0$. The maximum values of laser penetration rate $\mathrm{P}$ at a $\mathrm{T}_{\mathrm{uv}}$ value of $150 \mathrm{~min}$ were 0.34 and 0.31 for CR-39 and CN-85 detectors respectively. Another parameter used in the laser penetration technique is the penetration factor- $F_{p}$ which was calculated by the following equation:

$$
\mathrm{F}_{\mathrm{p}}=\ln \left(\mathrm{P}_{\mathrm{o}} / \mathrm{P}_{\mathrm{uv}}\right)
$$

where $\mathrm{P}_{\mathrm{o}}$ and $\mathrm{P}_{\mathrm{uv}}$ are the laser penetration rates-P for UVirradiated and unirradiated detectors, respectively.

The behaviour of the laser penetration factor $\mathrm{F}_{\mathrm{p}}$ with $\mathrm{T}_{\mathrm{uv}}$ is shown in Fig. 6 for CR-39 and CN-85 detectors. By determining the laser penetration rate $(\mathrm{P})$, the maximum response appear at $\mathrm{T}_{\mathrm{uv}}$ equal to $150 \mathrm{~min}$ for $\mathrm{CR}-39$ and $\mathrm{CN}-85$ detectors (Fig. 5).

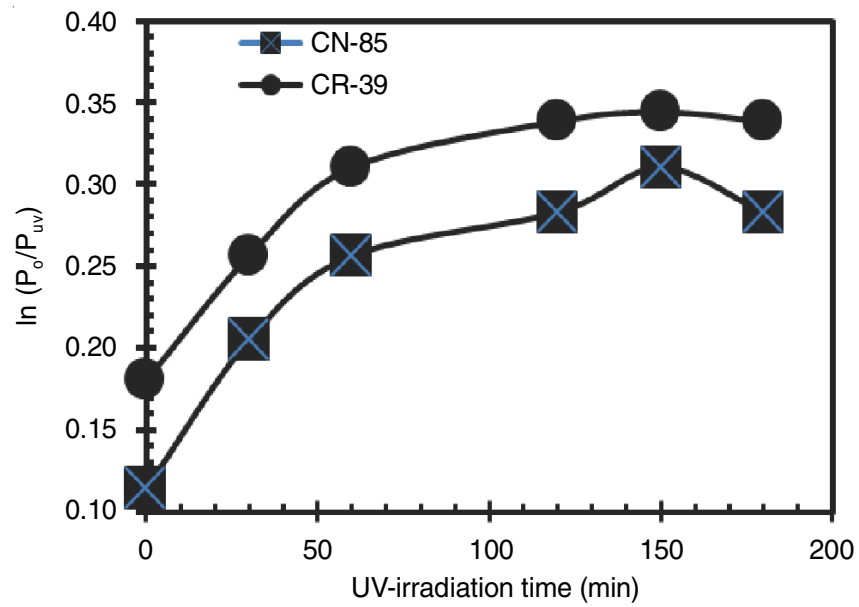

Fig. 5. Laser penetration rate- $\mathrm{P}$ in $\mathrm{CR}-39$ and $\mathrm{CN}-85$ detectors for different UV-exposure time- $\mathrm{T}_{\mathrm{uv}}(\mathrm{min})$ 

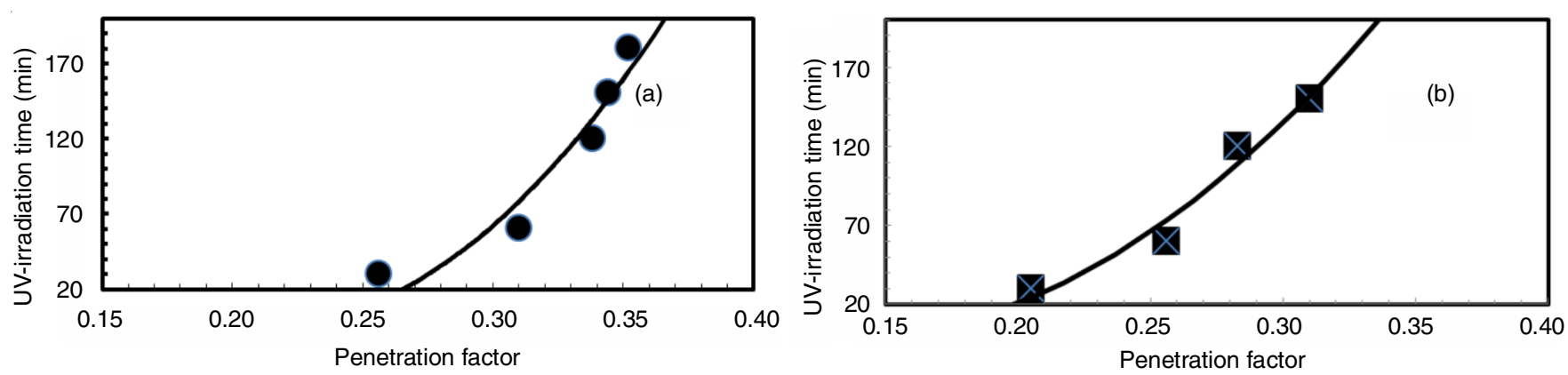

Fig. 6. Variation of penetration factor $-\mathrm{F}_{\mathrm{p}}$ as a function of UV-irradiation time- $\mathrm{T}_{\mathrm{uv}}$ (min) for (a) CR-39 detector and (b) CN-85 detector

The value of laser penetration factor $\mathrm{F}_{\mathrm{p}}$ increases with the increase of $\mathrm{T}_{\mathrm{uv}}$ for both detectors (CR-39 and CN-85). Laser penetration factor- $F_{p}$ values were 0.34 and 0.31 at irradiation time- $\mathrm{T}_{\text {uv }}$ of $150 \mathrm{~min}$ for CR-39 and CN-85 respectively. Shweikani et al. [12] determined the relationship between the change of transmission in UV-visible spectroscopy of CR-39 detector with exposure time of solar ultraviolet (SUV) and reported that this transmission decreases exponentially with exposure time up to $120 \mathrm{~min}$. The mathematical behaviour of $\mathrm{T}_{\mathrm{uv}}$ with laser penetration factor- $\mathrm{F}_{\mathrm{p}}$ is a polynomial relationship as shown in Table- 2 for $\mathrm{CR}-39$ and $\mathrm{CN}-85$ detectors.

\section{TABLE-2}

POLYNOMIAL RELATIONSHIP EQUATIONS FOR PENE-

TRATION FACTOR $\left(\mathrm{F}_{\mathrm{p}}\right)$ OF CR-39 AND CN-85 DETECTORS WITH UV-EXPOSURE TIME ( $\left.\mathrm{T}_{\text {uv }}\right)$ FROM 30-180 min

\begin{tabular}{ccc}
\hline Detector & Polynomial relations equation & $\begin{array}{c}\text { Responses } \\
\text { value } \mathrm{F}_{\mathrm{p}}\end{array}$ \\
\hline $\mathrm{CR}-39$ & $\mathrm{~T}_{\mathrm{uv}}=7058\left(\ln \mathrm{F}_{\mathrm{p}}\right)^{2}-2887.2 \ln \mathrm{F}_{\mathrm{p}}+293.9$ & 0.22 \\
$\mathrm{CN}-85$ & $\mathrm{~T}_{\mathrm{uv}}=4840.5\left(\ln \mathrm{F}_{\mathrm{p}}\right)^{2}-1281.9 \ln \mathrm{F}_{\mathrm{p}}+84$ & 0.15 \\
\hline
\end{tabular}

Table-2 shows the polynomial relation equations for the penetration factor $\mathrm{F}_{\mathrm{p}}$ with $\mathrm{T}_{\mathrm{uv}}$ regarding CR-39 and $\mathrm{CN}-85$ detectors. The responses of the penetration factor- $\mathrm{F}_{\mathrm{p}}$ for $\mathrm{CR}-$ 39 and $\mathrm{CN}-85$ detectors were 0.22 and 0.15 respectively. This indicates that the UV-irradiation response of the $\mathrm{CN}-85$ detector is greater than that of the CR-39 detector by using the laser penetration technique.

\section{Conclusion}

The quantitative molecular effects of UV-radiation on nuclear track detectors, $\mathrm{CN}-85$ and CR-39 detectors were used as parameters for calculating the radiation dose. UV-visible spectroscopy and $\mathrm{He}-\mathrm{Ne}$ laser penetration factors $\left(\mathrm{P}\right.$ and $\left.\mathrm{F}_{\mathrm{p}}\right)$ employed in manifesting this dose showed progressive linear relation with UV-exposure time, revealing the possibility of using these detectors in UV-radiation dosimetry.

\section{CONFLICT OF INTEREST}

The authors declare that there is no conflict of interests regarding the publication of this article.

\section{REFERENCES}

1. K.I. Mohammad and M.I. Azawe, Turk. J. Phys., 37, 182 (2013).

2. V. Kumar, R.G. Sonkawade, A.S. Dhaliwala and R. Mehra, Asian J. Chem., 21, S279 (2009).

3. V. Kumar, R.G. Sonkawade and A.S. Dhaliwala, Indian J. Pure Appl. Phys., 48, 466 (2010).

4. A.A. Al-Sàad and S.J. Abbas, Radiat. Meas., 34, 91 (2001); https://doi.org/10.1016/S1350-4487(01)00127-5.

5. E. Dhiaa and J. Al-bermany, Am. J. Sci. Res., 29, 130 (2011).

6. C.F. Wong and P. Hober, Nucl. Instrum. Methods Phys. Res., 203, 443 (1982);

https://doi.org/10.1016/0167-5087(82)90658-5.

7. M.A. Malek and C.S. Chong, Radiat. Meas., 35, 203 (2002); https://doi.org/10.1016/S1350-4487(01)00289-X.

8. D. Sinha, S. Ghosh, K.K. Dwivedi and D. Fink, Radiat. Eff. Def. Sol., 145, 45 (1998); https://doi.org/10.1080/10420159808220022.

9. L. Tavera, M. Balcázar, H. Matamoros and H. Carrasco, Radiat. Meas., 40, 259 (2005); https://doi.org/10.1016/j.radmeas.2005.06.011.

10. S. Prasher, M. Narwal, S. Rana and M. Kumar, Asian J. Chem., 21, 216 (2009).

11. M.S. Rafique, S. Bashir, A. Ajami and W. Husinsky, Appl. Phys., A Mater. Sci. Process., 100, 1183 (2010); https://doi.org/10.1007/s00339-010-5741-x.

12. R. Shweikani, G. Raja and A.A. Sawaf, Radiat. Meas., 35, 281 (2002); https://doi.org/10.1016/S1350-4487(02)00055-0.

13. T.C. Chun, Master Thesis, Investigations of the Effects of UV Irradiation on the Etching Behaviour of CR-39 Solid State Nuclear Track Detector, Department of Physics and Materials Sciences, University of Hong Kong (2007).

14. K.C.C. Tse, D. Nikezic and K.N. Yu, Radiat. Meas., 43, 98 (2008); https://doi.org/10.1016/j.radmeas.2008.03.029.

15. H.A. Al-Jobouri, M.B. Ben Hamida, N.F. Tawfiq and F.H. Taha, Am. $J$. Modern Energy, 1, 25 (2015).

16. M.F. Zaki, T.M. Hegazy and D.H. Taha, Arab. J. Nucl. Sci. Appl., 46, 201 (2013).

17. M. El Ghazaly and T.A. Al-Thomali, Radiat. Eff. Defects Solids, $\mathbf{1 6 8}$, 316 (2013); https://doi.org/10.1080/10420150.2012.745124.

18. Z. Lounis-Mokrani, M. Fromm, R. Barillon, A. Chambaudet and M. Allab, Radiat. Meas., 36, 615 (2003); https://doi.org/10.1016/S1350-4487(03)00211-7.

19. A.H. El-Farrash, A.M. Abedelghany, H.A. Yousef, M. Mekhimar and S.M. Najim, Res. J. Pharm. Biol. Chem. Sci., 6, 1049 (2015). 